\title{
Complex Formation between a Fluorescently-Labeled Polyelectrolyte and a Triblock Copolymer
}

\author{
Telma Costa, ${ }^{* \dagger}$ J. Seixas de Melo, ${ }^{\dagger}$ Maria da G. Miguel, ${ }^{\dagger}$ Björn Lindman, ${ }^{\dagger, *}$ and \\ Karin Schillén*,‡
}

Department of Chemistry, University of Coimbra, 3004-535 Coimbra, Portugal, and Division of Physical Chemistry, Center for Chemistry and Chemical Engineering, Lund University, P.O. Box 124, SE-22100 Lund, Sweden

Received: October 23, 2008; Revised Manuscript Received: February 17, 2009

\begin{abstract}
The association between a randomly pyrene labeled PAA polymer (PAAMePy55) and a PEO-PPO-PEO triblock copolymer (P123) in aqueous solutions of different $\mathrm{NaCl}$ concentrations and $\mathrm{pHs}$ has been studied by means of dynamic light scattering (DLS) and steady-state fluorescence spectroscopy at $40{ }^{\circ} \mathrm{C}$. At acidic $\mathrm{pH}$ values, in the low P123/PAAMePy55 molar ratio regime (i.e., at low P123 concentrations), the relaxation time distributions retrieved from the DLS data analysis were monomodal and very similar to those obtained for the pure PAAMePy55 solution. The apparent hydrodynamic radius of PAAMePy55 at low pH is $18 \mathrm{~nm}$. At higher molar ratios (i.e., at high $\mathrm{P} 123$ concentrations), still in the acidic pH regime, bimodal relaxation time distributions were obtained, where the fast relaxation mode is connected to the translational diffusion of free P123 micelles with a hydrodynamic radius obtained at infinite P123 dilution $\left(R_{\mathrm{H}, \mathrm{P} 123=0}\right)$ of $10-11 \mathrm{~nm}$. This value coincides perfectly with the hydrodynamic radius of the pure $\mathrm{P} 123$ micelles at $40{ }^{\circ} \mathrm{C}$, which was found to be ca. $10 \mathrm{~nm}$ at all $\mathrm{pH}$ values. The second mode corresponds to a complex consisting of one PAAMePy55 polymer chain and about $42 \mathrm{P} 123$ micelles and with a $R_{\mathrm{H}, \mathrm{P} 123=0}$ between 35 and $36 \mathrm{~nm}$ depending on $\mathrm{pH}$. At $\mathrm{pH}$ 9, the mixed system also presented bimodal relaxation time distributions. At this high $\mathrm{pH}$, the intermolecular association between PAAMePy55 and P123 is less strong than at acidic pH according to the steady-state fluorescence measurements. The fast mode is also in this case attributed to free P123 micelles whereas the second mode is related to the so-called "slow mode" commonly observed for polyelectrolyte solutions. In this system, it is related to the formation of multichain domains, that is, large domains formed by several PAAMePy55 chains that move in a common electrostatic field (i.e., a structure factor effect). The presence of P123 micelles does not lead to the total disruption of these domains. They may either contain entrapped P123 micelles or hydrophilic diblock impurities (originating from the P123 sample) that associate with the PAAMePy55 chains.
\end{abstract}

\section{Introduction}

The interaction between water-soluble polymers and surfactants is one of the most important and challenging field in the domain of colloidal science mostly because of its impact in industrial applications. ${ }^{1,2}$ Two of the main driving forces for the interaction are associated with the electrostatic and hydrophobic characteristics of the interacting polymer and the surfactant molecules. The polymer-surfactant interaction usually results in the formation of pearl-necklace structures (i.e., polymer chains decorated by surfactant micelles) that occur at lower surfactant concentrations than the critical micelle concentration $(\mathrm{cmc})$ of the surfactant alone. ${ }^{1-5}$ If the water-soluble polymer carries charges along its chain, it is called a polyelectrolyte. Polyelectrolytes combine unique properties of polymers and electrolytes; in solution, they are dissociated into polyvalent macroions (or polyions) and a large number of small ions of opposite charge (i.e., counterions). ${ }^{6}$ The high charge of the polyion produces an electrical field, which attracts the counterions producing the physical characteristics of an electrolyte. ${ }^{6}$ The conformation of an anionic polyelectrolyte in solution is

\footnotetext{
* Corresponding authors. E-mail address: Karin.Schillen@ fkem1.lu.se (K.S.); tcosta@ qui.uc.pt (T.C.).

${ }^{\dagger}$ University of Coimbra.

${ }^{\ddagger}$ Lund University.
}

strongly dependent on its degree of ionization $(\alpha)$ and interaction with the counterions. In the limit, it changes from a compact random coil $(\alpha=0)$ to a significantly expanded conformation at $\alpha=1$. The degree of ionization has also been shown to have a great influence on the interaction between polyelectrolytes and surfactants and a large number of studies have thus been performed, where the interaction with both ionic ${ }^{3,4}$ and nonionic surfactants $^{5,7-9}$ has been investigated. In both cases, the hydrophobic and electrostatic interactions showed to be of major importance.

The interaction between negatively charged polyelectrolytes, e.g. poly(acrylic acids), and oppositely charged surfactants is driven by electrostatic attractive interactions. On the other hand, the polyelectrolyte-nonionic surfactant association is driven by hydrophobic interactions at all $\mathrm{pH}$ values. ${ }^{5,7,8,10}$ In the nonionic form (low $\mathrm{pH}$ ), the compact coil is a preferential site of adsorption and a strong interaction between the polymer and the nonionic surfactants is observed. When the $\mathrm{pH}$ is increased, the polyelectrolyte chain expands due to the intrapolymer electrostatic repulsions, its hydrophobicity decreases and for this reason the interaction with the surfactant is strongly decreased., ${ }^{5,8}$ However, even at low $\mathrm{pH}$ values, where the interaction is likely to occur, the interaction has shown to be largely dependent on the molecular weight of both the surfactant and the polyelectrolyte. 
Although the interaction between polyelectrolytes and nonionic surfactants has been subject of detailed studies, few studies have focused on the interaction between polyelectrolytes and triblock copolymers of poly(ethylene oxide) (PEO) and poly(propylene oxide) (PPO). The triblock copolymers composed of a middle block of PPO and two PEO end blocks (PEO-PPOPEO) are available with varying chain length and block length ratio. Similarly to surfactants, the PEO-PPO-PEO block copolymers self-assembly in water, which is a thermodynamically good solvent for the PEO groups but a poor solvent for the PPO groups. ${ }^{11-15}$ In solution, they can exist as single copolymer chains (unimers), and upon increasing concentration (or temperature), micelle structures commence to be formed. ${ }^{11,12,16-18}$ The resultant micelle consists of dehydrated PPO blocks in the core surrounded by a water-swollen (hydrated) corona of PEO blocks as revealed by small-angle neutron and X-ray scattering measurements, $;^{19-25}$ see also, e.g., the review in ref 26 . The micelle formation is mainly governed by the PPO block length (the dependence on the PEO block length is less pronounced), the total molecular weight of the copolymer (foraconstantPPO/PEOratio), and the copolymerconcentration. ${ }^{11,13,27-29}$ The micellization temperature, as obtained from differential scanning calorimetry (DSC), decreases with the PPO block length. ${ }^{28-30}$ The transition temperature decreases also with increasing copolymer concentration ${ }^{11,13,29,30}$ or, expressed differently, cmc is very dependent on temperature.

Owning to the polydispersity of these copolymers (both chemical and molar mass hetereogenity), the unimer-to-micelle transition occurs over a broad temperature range, i.e. with a much less sharp critical micelle temperature $(\mathrm{cmt})$ or $\mathrm{cmc}$ than ordinary surfactants. This has been demonstrated by dynamic light scattering (DLS), ${ }^{17,18,31}$ ultrasonic speed measurements, ${ }^{20}$ DSC, ${ }^{20,30} \mathrm{NMR},{ }^{32}$ and model calculations. ${ }^{33,34}$ In this region, micelles of a defined size coexist with unimers. Furthermore, Hvidt et al. ${ }^{30,35}$ have demonstrated that the PEO-PPO-PEO copolymer samples contain lower size contaminants (hydrophilic PEO-PPO diblock copolymers), which are not included into the micelles, and if these impurities are removed by fractionation using interaction chromatography, the unimer-to-micelle transition sharpens in temperature. The effect of these diblock impurities on the structure of the cubic liquid crystalline phases of the triblock copolymer F127/water system has recently been reported. ${ }^{36}$ These may also play an important role in the polymer system studied in this work.

The intermolecular interaction and complex formation between poly(carboxylic acids), such as poly(acrylic acid), and their corresponding salts (polyacrylates) and PEO have been studied thoroughly in the literature. According to these investigations, which discuss the association as driven by hydrogen bonding, the stability and structure of the interpolymer complexes formed depends on the $\mathrm{pH}$, the ionic strength, the molecular weight, and whether the polymers carry hydrophobic groups. ${ }^{10,37,38}$ As we have discussed previously, in aqueous solutions, hydrogen bonding is not a driving force for association. ${ }^{39}$ On the other hand in a hydrophobic environment, it can play an important role on the association. Certainly, the interplay between electrostatic and hydrophobic interaction forces must also be present in these systems in addition to the hydrogen bonding.

The aim of the present study is to investigate the intermolecular interaction between a PAA polymer labeled with pyrene (PAAMePy55) and the $\mathrm{EO}_{20} \mathrm{PO}_{68} \mathrm{EO}_{20}$ block copolymer (P123) by means of DLS. This follows the previous study where the same system was investigated by fluorescence techniques. ${ }^{39}$ The micelle formation of $\mathrm{P} 123$ and the interaction with both ionic (SDS and CTAC) and nonionic $\left(\mathrm{C}_{12} \mathrm{EO}_{6}\right)$ surfactants were previously investigated by our group using differential scanning and titration calorimetry, static and dynamic light scattering, small-angle X-ray scattering, NMR-diffusiometry, and rheology. ${ }^{25,29,31,40-43}$ We will show that it is very fruitful to combine DLS and fluorescence spectroscopy in order to analyze in detail the intermolecular interactions in this polyelectrolyte-block copolymer system under various physical conditions such as $\mathrm{NaCl}$ concentration and $\mathrm{pH}$.

\section{Experimental Section}

Polymers and Sample Preparation. Poly(acrylic acid) (PAA) with a nominal molecular weight of $150000 \mathrm{~g} / \mathrm{mol}$ was purchased from Wako Chemicals as a $25 \%$ water solution. The pyrene-labeled PAA sample was kindly provided by Dr. Dan Anghel, and the synthesis followed the same route as described elsewhere. ${ }^{44}$ The Py content of labeled PAA corresponds to 55 monomers per chromophore per polymer chain. This sample is denoted PAAMePy55. The PEO-PPO-PEO triblock copolymer was a kind gift from BASF Corporation, Performance Chemicals, Mount Olive, NJ, and used without further treatment. The copolymer has the average composition $\mathrm{EO}_{20} \mathrm{PO}_{68} \mathrm{EO}_{20}$ (denoted P123, where P stands for "paste" and 3 for $30 \mathrm{wt} \%$ of PEO) and a nominal molar mass of $5750 \mathrm{~g} / \mathrm{mol}$. The P123 sample is polydisperse both in mass and composition. The GPC characterization performed in ref 31 showed that $10 \%$ of the material corresponded to low-molar mass components. In a recent investigation of the heterogeneity of these copolymers using size exclusion chromatography, it was found that the P123 copolymer sample may contain up to 26 wt $\%$ of smaller-size diblock impurities. ${ }^{35}$ Water purified by a Milli-Q system (Millipore Corporation, Bedford, MA) was used in all solutions used for the light scattering experiments.

The aqueous PAAMePy55 and P123 stock solutions were prepared and left to equilibrate overnight; the block copolymer solutions were prepared in a refrigerator at ca. $6{ }^{\circ} \mathrm{C}$. The PAAMePy55 stock solutions were prepared at different $\mathrm{pH}$ values using water that was previously filtered through $0.2 \mu \mathrm{m}$ filters from Whatman to exclude dust particles. The polyelectrolyte solutions were thereafter centrifuged at $3600 \mathrm{rpm}$ for 20 min to further decrease the amount of dust. The P123 stock solutions prepared at different $\mathrm{pH}$ values were filtered cold through $0.2 \mu \mathrm{m}$ filters from Whatman. The PAAMePy55-P123 solutions were mixed and left to equilibrate in the refrigerator a second night. All solutions were prepared by weighing. Prior to the measurement, the solution was equilibrated at room temperature for at least 20 min to avoid temperature jumps over the $\mathrm{cmt}$ of $\mathrm{P} 123^{31}$ and, thereafter, it was equilibrated at the measuring temperature for at least $20 \mathrm{~min}$. All measurements were performed at $40{ }^{\circ} \mathrm{C}$, which was controlled to within \pm 0.01 ${ }^{\circ} \mathrm{C}$ by a F32 Julabo heating circulator.

Dynamic Light Scattering. The setup used for the DLS measurements is an ALV/DLS/SLS-5000F, CGF-8F based compact goniometer system from ALV-GmbH, Langen, Germany. A more detailed description about the instrumentation can be found in ref 31 with the difference being that cisdecahydronaphthalene is used as refractive-index-matching liquid. The laser is a CW frequency-doubled diode-pumped $\mathrm{Nd}$ : YAG solid-state Compass-DPSS laser from COHERENT, Inc., Santa Clara, CA, that operates at a wavelength $(\lambda)$ of $532 \mathrm{~nm}$ with a fixed output power of $400 \mathrm{~mW}$, which can be varied using an attenuator from Newport Inc. The DLS measurements were performed at different scattering angles $\left(\theta=50^{\circ}-130^{\circ}\right)$ 


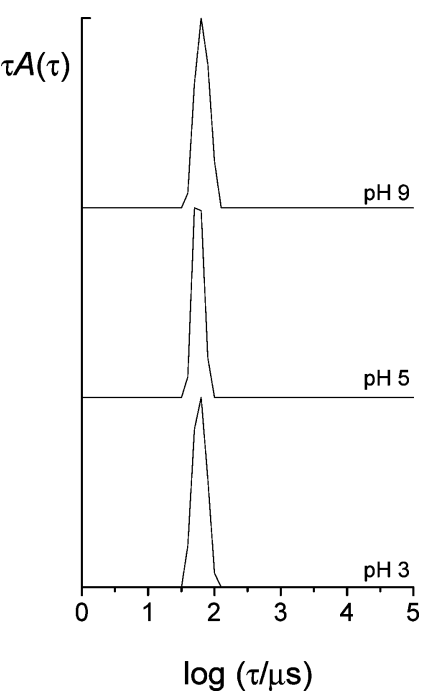

Figure 1. Relaxation time distributions obtained by regularized inverse Laplace transformation of the corresponding intensity correlation functions from DLS for the $1 \mathrm{wt} \%$ P123 block copolymer at three different $\mathrm{pH}$ values $\left(\mathrm{pH} 3,5\right.$, and 9) at $40{ }^{\circ} \mathrm{C}$ and measured at $\theta=$ $90^{\circ}$

This corresponds to the $q$ range of $1.33 \times 10^{7}-2.85 \times 10^{7} \mathrm{~m}^{-1}$, where $q$ is the magnitude of the scattering vector, which in case of dilute systems is given by $q=4 \pi n_{0} \sin (\theta / 2) / \lambda$, in which $n_{0}$ is the refractive index of the solvent (in this case water, $n_{0}=1.332$ ). The output of the DLS experiment is the normalized time correlation function (pseudocross or auto) of the scattered intensity, $g^{(2)}(t)$ (or rather $g^{(2)}(t)-1$ ). The normalized electric field correlation function $g^{(1)}(t)$, which is related to $g^{(2)}(t)$ by Siegert's relation, of a solution of polydisperse particles may be expressed as a Laplace transformation of the relaxation time distribution: ${ }^{45,46}$

$$
g^{(1)}(t)=\int_{0}^{\infty} \tau A(\tau) \exp (-t / \tau) \mathrm{d} \ln \tau
$$

where $\Gamma=\tau^{-1}$ is the relaxation frequency or rate, which is obtained from the first moment of the distribution.

A nonlinear regularized inverse Laplace transformation procedure, REPES, ${ }^{45,47}$ was used to directly analyze the experimental $g^{(2)}(t)-1$ functions to obtain the distribution of relaxation times, $A(\tau)$, where $\tau$ is the relaxation time. In this study, the relaxation time distributions are presented as $\tau A(\tau)$ $=\log (\tau / \mu \mathrm{s})$ for equal-area representation. ${ }^{48}$

Steady-State Fluorescence. Fluorescence spectra were recorded on a Jobin-Ivon SPEX Fluorog 3-22 spectrometer. The fluorescence spectra were corrected for the wavelength response of the system. The solutions for the fluorescence experiments were prepared in a similar way as for the DLS experiments with the exception of the filtering and centrifuging processes.

\section{Results}

Dynamic Light Scattering. P123 Block Copolymer in Aqueous Solution. Dynamic light scattering measurements were performed on $1 \mathrm{wt} \%$ P123 block copolymer solutions at three different $\mathrm{pH}$ values $(3,5$, and 9$)$ and at $40{ }^{\circ} \mathrm{C}$. The relaxation time distributions $[\tau A(\tau)$ vs $\log (\tau / \mu \mathrm{s})]$, obtained from the regularized inverse Laplace transformation of the measured time correlation functions of the scattered intensity are presented in Figure 1. As can be observed from Figure 1, the relaxation time distributions consist of a narrow and well-defined peak. The relaxation rate $\Gamma$ of this single relaxation mode shows a linear dependence with the square of the magnitude of the scattering vector $q^{2}$ (data not shown). This indicates that this mode corresponds to the translational diffusion process of the P123 micelles. The P123 concentration used is far above the $\mathrm{cmc}$ values of the $\mathrm{P} 123$ at $40{ }^{\circ} \mathrm{C}$, which are obtained from $\mathrm{DSC}^{29,31}$ and fluorescence ${ }^{39}$ measurements are $0.2 \times 10^{-3}$ wt $\%(3.48 \times$ $\left.10^{-7} \mathrm{M}\right)$ and $1.8 \times 10^{-6} \mathrm{M}$, respectively. The apparent mutual diffusion coefficient $(D)$ of the P123 micelles can thus be obtained from the slope of $\Gamma$ vs $q^{2}$ according to the following: ${ }^{49}$

$$
D=\left(\frac{\Gamma}{q^{2}}\right)_{q \rightarrow 0}
$$

$D$ is concentration dependent both due to hydrodynamic and intermolecular interactions. The diffusion coefficient at infinite dilution at $c_{\mathrm{P} 123}=0, D_{0}$ (with its associated error), can be estimated from a diagram of $D$ as a function of the P123 concentration $c_{\mathrm{P} 123}$ in each case (data not shown). The hydrodynamic radius of the P123 micelles at infinite dilution is thereafter directly obtained by the Stokes-Einstein equation:

$$
R_{\mathrm{H}}=\frac{k_{\mathrm{B}} T}{6 \pi \eta_{0} D_{0}}
$$

where $k_{\mathrm{B}}$ is Boltzmann's constant, $T$ is the absolute temperature, and $\eta_{0}$ is the viscosity of the solvent $\left(\eta_{0}=0.6449 \times 10^{-3}\right.$ Pa s for water at $40{ }^{\circ} \mathrm{C}$ ).

The obtained hydrodynamic radius of the P123 micelles, at $40^{\circ} \mathrm{C}$, was found to be about $10 \mathrm{~nm}$ at all $\mathrm{pH}$ values (i.e., 10.8 $\pm 0.3 \mathrm{~nm}$ at $\mathrm{pH} 3,9.8 \pm 0.1 \mathrm{~nm}$ at $\mathrm{pH} 5$ and $9.9 \pm 0.1 \mathrm{~nm}$ at $\mathrm{pH} 9$, where the error is given as one standard deviation $(\sigma)$ estimated from diffusion-coefficient determinations at different angles). With intensive light scattering studies of the P123 block copolymer, performed at different concentrations and temperatures, similar values of the hydrodynamic radius were obtained at $40{ }^{\circ} \mathrm{C}$ (the discrepancies are due to the different batches used). ${ }^{31,42}$ The presence of inorganic salts, such as $\mathrm{NaCl}$, are known to reduce the $\mathrm{cmc}$ and the $\mathrm{cmt}$, as well as to induce the micelle-to-rod transition, i.e., to induce the micellar growth, due to the dehydration of the PEO blocks leading to a decrease in the spontaneous curvature of the block copolymer film. However, in our study the presence of salt $(1.4$ and $10 \mathrm{mM}$ of $\mathrm{NaCl}$, at acidic and basic $\mathrm{pH}$ values, respectively) does not affect the size of the P123 block copolymer micelles. Recent studies on the influence of $\mathrm{NaCl}$ concentration on the sphere-to-rod transition, of the P123 block copolymer (1 wt \%) with $10 \%$ ethanol, revealed that the apparent translational diffusion coefficient decreases from $\sim 2.7 \times 10^{-11}$ to $\sim 2.5 \times 10^{-11} \mathrm{~m}^{2} / \mathrm{s}$ when the $\mathrm{NaCl}$ concentration increases from 0 to $0.5 \mathrm{M} .{ }^{50}$ This corresponds to an increase of $\sim 1 \mathrm{~nm}$ in the hydrodynamic radius of the micelle. More recently, Denkova et al. ${ }^{51}$ studied the effect of several inorganic salt $(\mathrm{KF}, \mathrm{KCl}, \mathrm{KI}, \mathrm{LiCl}$, and $\mathrm{CsCl})$ on the P123 micelle structure in solution. $\mathrm{LiCl}$ and $\mathrm{KI}$ showed to have little influence on the micellar structure when compared with the other salts where sphere-to-rod transition was shown to be promoted by their presence in solution. However, the concentrations used in both studies are well above the concentrations used in our study [2 $\mathrm{M}$ vs 0.001 (at $\mathrm{pH} 3-5$ ) or $0.01 \mathrm{M}$ (at $\mathrm{pH}$ 9)]. Therefore, we can infer that for the low salt concentrations used in this study no significant increase would be expected in the $R_{\mathrm{H}}$. 


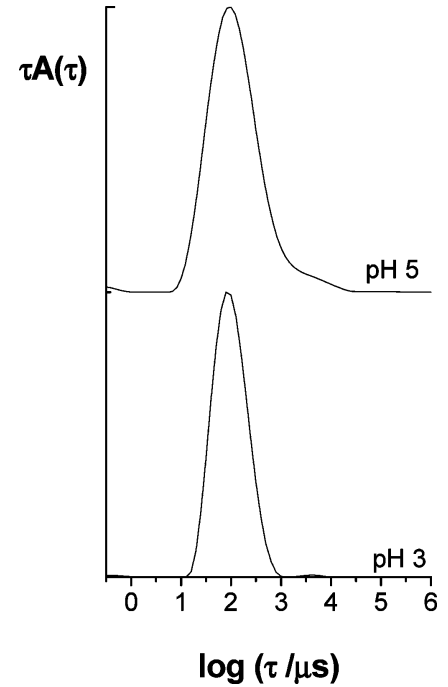

Figure 2. Relaxation time distributions for $0.20 \mathrm{wt} \%$ of PAAMePy55 at $\mathrm{pH} 3$ (bottom curve) and 5 (top curve) in the presence of $1.4 \mathrm{mM}$ of $\mathrm{NaCl}$. Measurements at $40{ }^{\circ} \mathrm{C}$ and at $\theta=110^{\circ}$.

PAAMePy55 Polymer in Aqueous Solution. The aqueous PAAMePy55 polymer solutions were also studied at three different $\mathrm{pH}$ values $(3,5$, and 9$)$ and at $40{ }^{\circ} \mathrm{C}$ by using DLS. The intensity correlation functions obtained for the salt-free PAAMePy55 solutions were multiexponential, and the relaxation time distributions obtained from the Laplace inversion analysis were therefore multimodal. The analyses were carried out with carefulness considering the difficulties of this type of calculations. However, the REPES algorithm used here is more robust than that of CONTIN. ${ }^{45}$ At all $\mathrm{pH}$ values, although more pronounced at intermediate and high $\mathrm{pH}$, two main modes were obtained (data not shown): a fast mode in addition to a slow mode (with a large amplitude) positioned at higher relaxation times. On the basis of the $q^{2}$ dependences of $\Gamma$ (see eq 2), the fast and slow modes can be attributed to two different translational diffusive processes. These modes are characteristic for DLS results on polyelectrolyte solutions. ${ }^{52}$ In previous studies, the fast mode has been attributed to the coupled diffusion of a polyion and counterions in a common electrostatic field where the polyion experiences an electric force due to the concentration fluctuations of the surrounding counterions. ${ }^{53-55}$ The translational diffusive motion as measured by DLS will therefore become faster due to the polyion-counterion interactions. ${ }^{56}$ Furthermore, the apparent hydrodynamic radius $R_{\mathrm{H}, a p p}$ obtained from the slow diffusive mode (using eqs 2 and 3 ) confirms that this translational mode cannot be due to the diffusion of a single PAAMePy55 chain, but instead to the diffusion of several PAAMePy55 chains that move together forming large domains in the solution (i.e., a static structure factor effect) as the $R_{\mathrm{H} \text {,app }}$ value obtained is much larger than that of the single chain. This multimodal behavior is very common in highly charged polyelectrolyte systems and has been extensively studied by Sedlák, ${ }^{53-55,57-66}$ who also showed that the presence of low molecular weight electrolytes has a strong effect on the obtained relaxation time distributions.

In the PAA system at low $\mathrm{pH}$ values, the polyelectrolyte is less charged ( $\alpha$ is low) and the slow mode effect is therefore less pronounced than at $\mathrm{pH} 9$ (as will be shown below in Figure $3)$. Figure 2 shows the relaxation time distributions of PAAMePy55 polymer in the presence of $1.4 \mathrm{mM} \mathrm{NaCl}$ at $\mathrm{pH} 3$ and 5 . As can be seen, the distributions are dominated by one main peak and the amplitude of the slow mode has strongly decreased

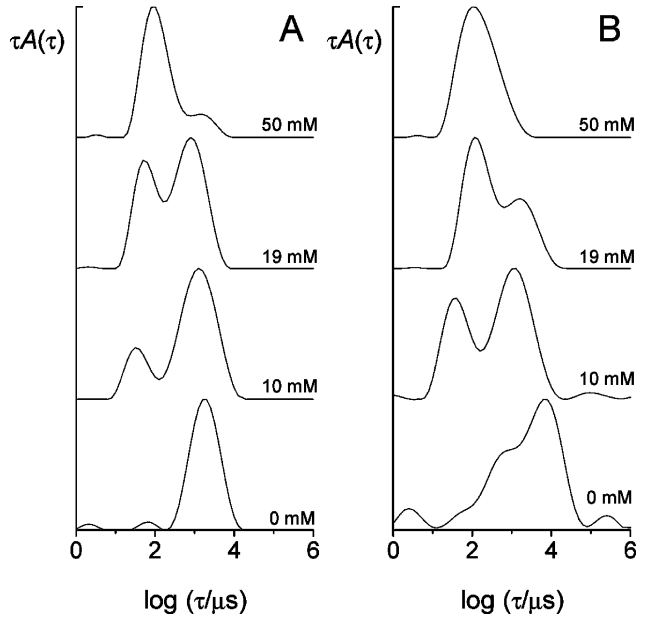

Figure 3. Relaxation time distributions for (A) $0.20 \mathrm{wt} \%$ PAA and (B) $0.20 \mathrm{wt} \%$ PAAMePy55 at $\mathrm{pH}=9$ with different $\mathrm{NaCl}$ concentrations (ranging from 0 to $50 \mathrm{mM}$ ). Measurements at $40{ }^{\circ} \mathrm{C}$ and at $\theta=$ $110^{\circ}$.

as compared to the situation in the absence of $\mathrm{NaCl}$ (see Figure 3 below). This is the evidence that the domains have been almost totally vanished. The relaxation rate of the main mode shows a linear $q^{2}$ dependence and corresponds to the translational diffusion of the single PAAMePy55 polymer chain with an $R_{\mathrm{H}, \text { app }}$ value of approximately $18 \mathrm{~nm}\left[R_{\mathrm{H} \text {,app }}=18 \pm 2 \mathrm{~nm}( \pm \sigma)\right.$, at acidic $\mathrm{pH}$ values]. A similar value $\left(R_{\mathrm{H}, \mathrm{app}} \sim 20 \mathrm{~nm}\right)$ was found by Fundin et al. ${ }^{4}$ for a polyacrylate chain, with $M_{\mathrm{w}}=90 \mathrm{~kg} /$ $\mathrm{mol}$, in the presence of $20 \mathrm{mM}$ of $\mathrm{NaBr}$.

In Figure 3, we compare the relaxation time distributions of the unlabeled PAA in water at $\mathrm{pH} 9$ and at various ionic strengths with those of the pyrene-labeled PAA. Under saltfree conditions and low ionic strengths, both systems display complex multimodal relaxation time distributions. The fast and the slow modes are, as described above, the result from the coupled diffusion of the polyion and the counterions and from the formation of multichain domains, respectively. These latter structures present $R_{\mathrm{H}, \text { app }}$ values in the range of $80-200 \mathrm{~nm}$ (depending on the $\mathrm{NaCl}$ concentration). An estimation of the hydrodynamic radius of a fully ionized PAA chain of 150000 $\mathrm{g} / \mathrm{mol}$ at $\mathrm{pH} 9$ and at low ionic strength, gives $42-50 \mathrm{~nm}$ depending on the geometrical shape used (semitorus or torus), which suggests that these domains are composed of several chains. ${ }^{67}$ Increasing the salt concentration from 10 to $20 \mathrm{mM}$ causes a shift in the relaxation time of the two modes: the slow diffusion process becomes faster and the fast process slower. As the salt concentration increases up to $50 \mathrm{mM}$, the charges of the PAA polymer chain are almost totally screened, leading to a more compact polymer conformation. Although the slow mode is still present in the relaxation time distribution, it looses weight and the "uncharged" PAA chain is the main scattering object in solution. It is worth noting that in the absence of $\mathrm{NaCl}$, a third middle mode was also obtained, which could be related to the "interaction mode" that Sedlák has described to be present in a two-polymer system (a polydisperse system as is the case of that presently studied) ${ }^{55,58,59}$ However, we do not wish to further pursue this issue since the regularized inverse Laplace transformation procedure REPES could still produce small peaks that are artifacts.

The same behavior as the unlabeled PAA system at $\mathrm{pH} 9$ is observed for the PAAMePy55 system at pH 9 (Figure 3B). At $10 \mathrm{mM}$ concentration of $\mathrm{NaCl}$, the relaxation time distribution shows two main modes (both with a $q^{2}$ dependence) corre- 
sponding to the $R_{\mathrm{H}, \mathrm{app}}$ values of $7( \pm 0.9) \mathrm{nm}$ and $135( \pm 20)$ $\mathrm{nm}$, respectively. These modes are most likely the characteristic fast and slow modes of the PAAMePy55 system at pH 9 (similar to the unlabeled PAA system). This appearance of a bimodal distribution can thus be considered the "fingerprint" of the PAAMePy55 system and will be used in the forthcoming discussion of the mixed PAAMePy55-P123 system. Furthermore, we believe that the minor difference in relative amplitude observed in the relaxation time distributions of the PAAMePy55 and the PAA polymers is clearly connected to the hydrophobic labeling of the former polymer. Indeed, it seems clear from the above results that the hydrophobic interactions between the pyrene polymer groups, together with the screening of the electrostatic interactions due to the presence of $\mathrm{NaCl}$, results in an even more compact conformation in the case of PAAMePy55 than in the case of the untagged PAA. At $50 \mathrm{mM} \mathrm{NaCl}$, the two modes merge into a single one, and monomodal relaxation time distributions are obtained. This single mode corresponds to the translation diffusion of a single PAAMePy55 chain with a $R_{\mathrm{H} \text {,app }}$ of $21.0 \pm 0.9 \mathrm{~nm}( \pm \sigma)$.

This value is very similar to that obtained for the corresponding PAAMePy55 polymer at acidic $\mathrm{pH}$ values, i.e. $18 \mathrm{~nm}$ (see Figure 2). Therefore, we may conclude that the screening of the electrostatic interactions by increasing the salt concentration leads to the disruption of the PAAMePy55 multichain domains and hence a less pronounced structure factor.

PAAMePy55-P123 Mixed System. After the investigation of the $\mathrm{pH}$ dependence and the response to simple salt addition of the P123 block copolymer and PAAMePy55 polyelectrolyte neat systems, DLS experiments were carried out on the PAAMePy55-P123 mixed system. A small amount of $\mathrm{NaCl}$ was used to avoid further complications related to the electrostatic interactions as described above, but still not too much to screen the interactions between the charges within the polyelectrolyte chains. The $\mathrm{NaCl}$ concentration used in all experiments was $1.4 \mathrm{mM}$ at $\mathrm{pH} 3$ and 5 and $10 \mathrm{mM}$ at $\mathrm{pH} 9$.

In the low P123 concentration regime (low P123/PAAMePy55 molar ratios, $\left.n_{\mathrm{P} 123} / n_{\mathrm{PAAMeP} 55}=\mathrm{MR}\right)$ the relaxation time distributions were, at all investigated $\mathrm{pH}$ values, very similar to those obtained for the pure PAAMePy55 solution (with similar $R_{\mathrm{H} \text {,app }}$ values) (data not shown). However, due to the limited sensitivity of the DLS method, an association between the P123 unimers and the PAAMePy55 polymer chain cannot be excluded in this region. In the high molar ratio regime, on the other hand, where low $I_{\mathrm{E}} / I_{\mathrm{M}}$ ratio values are obtained from fluorescence measurements (ref 39; see also Figure 8 below), the intermolecular association is clearly seen in the DLS results. The measurements in this regime were performed using four different sets of samples, each with a fixed PAAMePy55 concentration and with varying P123 concentration from $\sim 1.5$ to $\sim 4$ wt $\%$. The PAAMePy55 concentrations used were 0.005 , $0.010,0.015$, and $0.02 \mathrm{wt} \%$. The relaxation time distributions obtained for the $0.015 \mathrm{wt} \%$ PAAMePy55 solution with varying P123 concentration at pH 3, 5, and 9 are presented in Figure 4. Also included in the figures are the distributions of the pure P123 and PAAMePy55 solutions at each pH, respectively.

At low $\mathrm{pH}$ values, the relaxation time distributions show two diffusive modes; the $q^{2}$ dependences of the fast and slow modes were analyzed in the angular range from $70^{\circ}$ to $130^{\circ}$ (see Figure 5 for the $\mathrm{pH} 3$ case). The corresponding translational diffusion coefficients were obtained from the slopes (i.e., by application of eq 2 ) and the $R_{\mathrm{H} \text {,app }}$ values were calculated from eq 3 .

Comparing the relaxation time distributions of the PAAMePy55-P123 system with those of the pure P123 micellar solutions
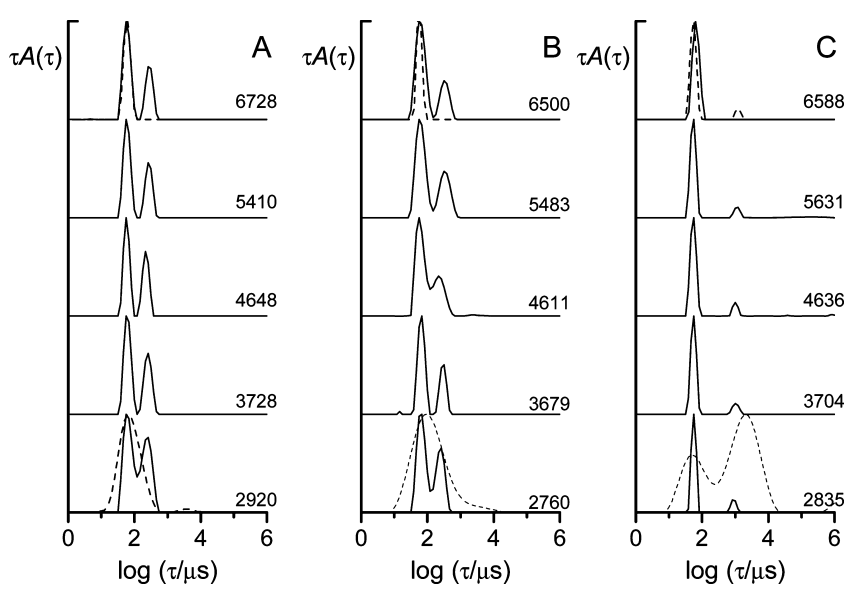

Figure 4. High P123/PAAMePy55 molar ratio regime at $40{ }^{\circ} \mathrm{C}$. Relaxation time distributions for molar ratios ranging from $\sim 2700$ to 6728: (A) at pH 3 (and $1.4 \mathrm{mM} \mathrm{NaCl}$ ), (B) pH 5 (and $1.4 \mathrm{mM} \mathrm{NaCl}$ ), and $(\mathrm{C}) \mathrm{pH}=9$ (and $10 \mathrm{mM} \mathrm{NaCl}$ ). In terms of concentration, the presented relaxation time distributions correspond to a constant PAAMePy55 concentration ( $0.015 \mathrm{wt} \%)$ with varying P123 concentration (from 1.5 to $3.5 \mathrm{wt} \%$ ). The dashed lines correspond to the distributions of P123 in $\mathrm{NaCl}$ solution (P123 micelles, $1.74 \mathrm{mM}$, top)

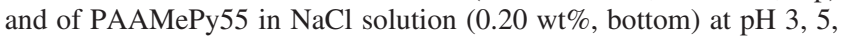
and 9 , respectively. Measurements are at $40^{\circ} \mathrm{C}$ and at $\theta=90^{\circ}$.

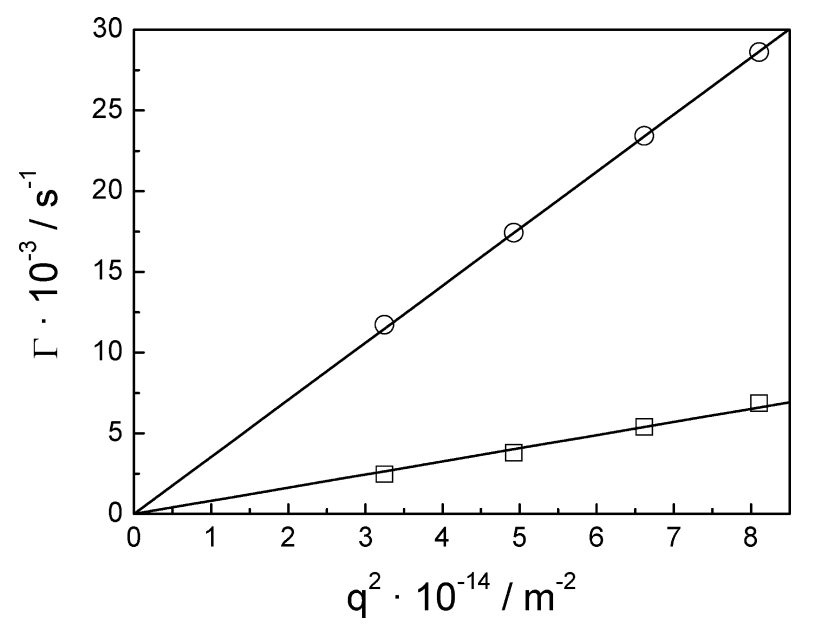

Figure 5. Dependence of the relaxation rates on the magnitude of the scattering vector squared for $0.015 \mathrm{wt} \%$ PAAMePy55 in $1.4 \mathrm{mM} \mathrm{NaCl}$ with $3.0 \mathrm{wt} \% \mathrm{P} 123(\mathrm{MR}=5410)$ at $\mathrm{pH}=3$ : $(\mathrm{O})$ fast mode, attributed to the P123 micelles; $(\square)$ slow mode, attributed to the PAAMePy-P123 complexes.

in Figure 4, we observe that the fast mode of the mixed system completely overlaps the relaxation time distribution of the pure $\mathrm{P} 123$. Hence, this mode corresponds to the translational diffusion of the free P123 micelles in the mixed solution. The data presented in Figure 5 give $R_{\mathrm{H} \text {,app }}=10.0 \pm 0.1 \mathrm{~nm}$ for the fast mode, where the error is given as one standard deviation. Another observation is that the second (slower) mode of the mixed system does not completely overlap with the relaxation mode of the pure PAAMePy55 polymer at low $\mathrm{pH}$, i.e., the former is positioned at longer times than the latter (compare Figure 2 with Figure 4A and B). This decrease in the diffusion coefficient of the PAAMePy55 polymer chain in the mixed case at low $\mathrm{pH}$ means that there is an increase of the PAAMePy55 hydrodynamic radius. Hence, we interpret this second mode to be associated to a complex formed between PAAMePy55 and P123. For a fixed PAAMePy55 concentration (0.015 wt \%), at $\mathrm{pH} 3$, the corresponding $R_{\mathrm{H} \text {,app }}$ varies between $37.6 \pm 0.4$ and $45 \pm 3 \mathrm{~nm}$ depending on the P123 concentration. These values 


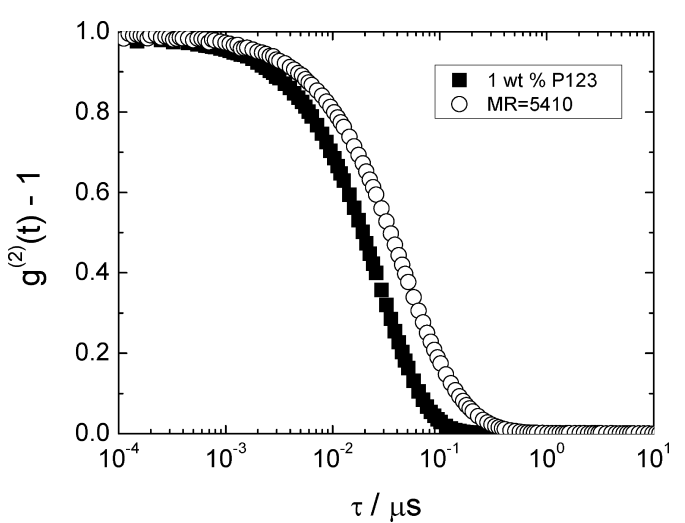

Figure 6. Intensity correlation functions of the pure P123 solution and of the mixed system $(\mathrm{MR}=5410)$ in the presence of $1.4 \mathrm{mM}$ of $\mathrm{NaCl}$ and at $\mathrm{pH} 3, \theta=90^{\circ}$ and $T=40^{\circ} \mathrm{C}$.

are significantly higher than those obtained for the pure PAAMePy55 polymer chain $\left(R_{\mathrm{H}, \text { app }} \sim 18 \mathrm{~nm}\right.$ at low $\left.\mathrm{pH}\right)$. This expansion of the polymer chain, which is in agreement with the fluorescence results, where a decrease of the $I_{\mathrm{E}} / I_{\mathrm{M}}$ ratio was observed $^{39}$ (see Figure 8 below), clearly indicates that P123 micelles associate with PAAMePy55.

In Figure 6, two representative intensity correlation functions are displayed, one for a mixed solution and one for a pure P123 solution in the presence of $1.4 \mathrm{mM}$ of $\mathrm{NaCl}$ (both at $\mathrm{pH} 3$ ). It is clearly observed that the correlation function of the mixed system is shifted toward longer times and therefore contains an additional slow relaxation process, which shows the complex formation between the two species in the solution.

At $\mathrm{pH}$, the relaxation time distributions are very different from those obtained at $\mathrm{pH} 3$ and 5 (Figure 4). Two modes are still present; the faster is due to the diffusion of free P123 micelles in the mixed solution, as was observed at acidic $\mathrm{pH}$ values. However, the slow mode is not due to the diffusion of individual PAAMePy55-P123 complexes, since it is much slower than that observed at acidic $\mathrm{pH}$ values. This mode belongs to the "fingerprint" relaxation pattern of the pure PAAMePy55 polymer system mentioned above. This becomes evident when comparing this distribution to that of the pure PAAMePy55 system at pH 9 (see Figure 3B). The slow mode, which is present in the mixed system, may thus be related to the (slow) mode caused by the multichain domains due to electrostatic interactions that are present in the pure PAAMePy55 system. The fluorescence results $\left(I_{1} / I_{3} \text { and decay times }\right)^{39}$ obtained at $\mathrm{pH} 9$ are clearly indicative of interaction between the PAAMePy55 and P123 block copolymer, although weaker than acidic $\mathrm{pH}$ values. The DLS data are more difficult to analyze and which will be further discussed below.

Complex Formation and Complex Size. In the high molar ratio regime and at acidic $\mathrm{pH}$ values, a clear association between the PAAMePy55 polymer and the P123 micelles is observed when examining the relaxation time distributions (Figure 4) and the intensity correlation functions (Figure 6). Due to the high P123 concentrations used, the presence of free micelles is also detected in addition to the slower mode associated with the PAAMePy55-P123 complex as previously mentioned. Four sets of experiments were carried out using four fixed PAAMePy55 polymer concentrations and varying the P123 concentration, at the three $\mathrm{pH}$ values studied. For each fixed PAAMePy55 concentration, the fast and slow diffusion coefficients $\left(D_{\text {fast }}\right.$ and $\left.D_{\text {slow }}\right)$ associated are plotted as a function of the P123 concentration and the resultant graph is presented in Figure 7.

We observe in Figure 7 that at all $\mathrm{pH}$ values $(\mathrm{pH} 5$ data not shown) the two diffusion coefficients both display a linear
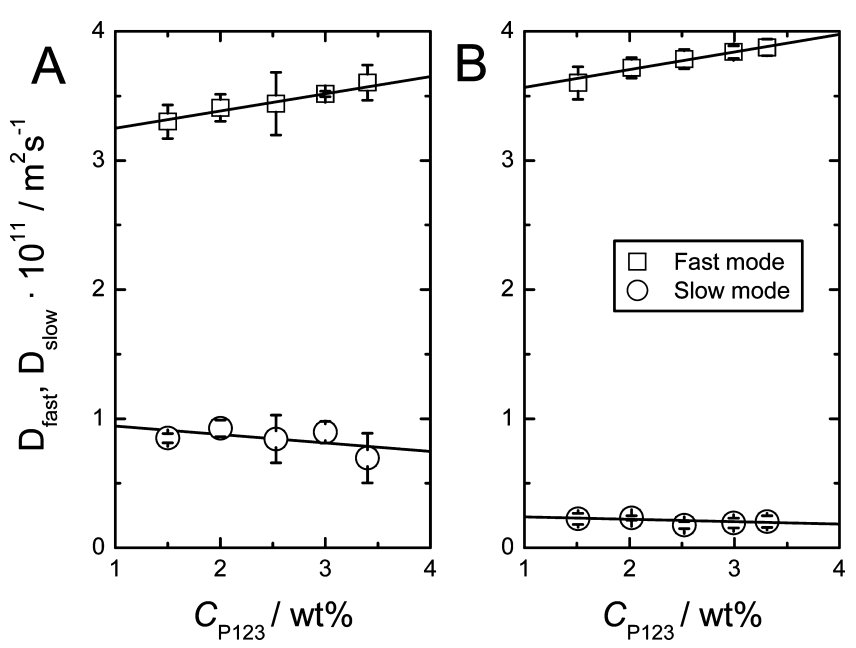

Figure 7. Diffusion coefficients of the PAAMePy55-P123 system as a function of $\mathrm{P} 123$ concentration, at $\mathrm{pH} 3$ (and $1.4 \mathrm{mM} \mathrm{NaCl}$ ) (A) and at $\mathrm{pH} 9$ (and $10 \mathrm{mM} \mathrm{NaCl}$ ) (B). The data points represent the averages of $D$ values obtained at different PAAMePy 55 concentrations: $0.005,0.01,0.015$, and $0.02 \mathrm{wt} \%$ and the error bars represent \pm one standard deviation; $T=40{ }^{\circ} \mathrm{C}$.

dependence on the P123 concentration and that they appear to be independent of the PAAMePy55 concentration in the range of dilute concentrations studied. The dependence of the diffusion coefficients on the P123 concentration can be expressed by the following equation:

$$
D_{\text {fast }, \text { slow }}=D_{\mathrm{P} 123=0}^{\text {fast,slow }}\left(1+k_{\text {slope }} C_{\mathrm{P} 123}+\ldots\right)
$$

where $D_{\mathrm{P} 123=0}^{\text {fast }}$ and $D_{\mathrm{P} 123=0}^{\text {slow }}$ are the apparent fast and slow diffusion coefficients at infinite dilution of P123 but at a finite concentration of PAAMePy55, and $C_{\mathrm{P} 123}$ is the P123 block copolymer concentration. The term $k_{\text {slope }}$ has a similarity to the dynamic virial coefficient, ${ }^{49}$ but in this study it is merely interpreted as the slope of the linear function.

Since the diffusion coefficients are independent of the PAAMePy55 concentration, the values were therefore averaged and only one linear fit of $D_{\text {fast }}$ and $D_{\text {slow }}$, respectively, to $c_{\mathrm{P} 123}$ was performed (Figure 7). The extrapolation of the fast diffusion coefficient to $C_{\mathrm{P} 123}=0$ thus gives the diffusion coefficient $D_{\mathrm{P} 123=0}^{\text {fast }}$ and, consequently, $R_{\mathrm{H}, \mathrm{P} 123=0}^{\text {fast }}$ (from eq 3 ). At $\mathrm{pH} 3$ and $5, R_{\mathrm{H}, \mathrm{P} 123=0}^{\text {fast }}=11.4 \pm 0.3$, and at $\mathrm{pH} 9$, it is $10.3 \pm 0.1 \mathrm{~nm}$, thus displaying an almost constant size with $\mathrm{pH}$. These values are very similar to the different radii values of the pure P123 micelle in water obtained at $40{ }^{\circ} \mathrm{C}$ in previous studies by using DLS $\left(9.8 \mathrm{~nm}^{31}\right.$ and $\left.10.1 \mathrm{~nm}^{42}\right)$ and SAXS $\left(10 \mathrm{~nm}^{25}\right)$. We may thus conclude that free P123 micelles (i.e., micelles that do not associate with the PAAMePy55 polymer chains) must be present in mixed solution. This observation is not surprising since the $\mathrm{P} 123$ concentrations are well above the $\mathrm{cmc}$ of $\mathrm{P} 123$ at $40{ }^{\circ} \mathrm{C}$ $\left(1.8 \times 10^{-6} \mathrm{M}\right)$, and it is also above the concentration at which the PAAMePy55 and the P123 micelles start to associate (3.5 $\times 10^{-6}$ and $6.7 \times 10^{-6} \mathrm{M}$, at $\mathrm{pH} 3.6$ and 5 , respectively), determined from the fluorescence measurements (see Figure 8 below and ref 39).

Similarly, the slow diffusion coefficients at $C_{\mathrm{P} 123}=0, D_{\mathrm{P} 123=0}^{\text {slow }}$, and the hydrodynamic radii $R_{\mathrm{H}, \mathrm{P} 123=0}^{\text {slow }}$ associated with them, were estimated at all three $\mathrm{pH}$ values. Also in this case, $R_{\mathrm{H}, \mathrm{P} 123=0}^{\mathrm{sll}=0}$ can be considered to be constant at acidic $\mathrm{pH}$ values within the experimental error $\left(R_{\mathrm{H}, \mathrm{P} 123=0}^{\text {slow }}=35 \pm 5 \mathrm{~nm}\right.$ at $\mathrm{pH} 3$ and $36 \pm 6$ $\mathrm{nm}$ at $\mathrm{pH} 5$ ), with an average value of $\left\langle R_{\mathrm{H}, \mathrm{P} 123=0}^{\text {slow }}\right\rangle=36 \mathrm{~nm}$. At 


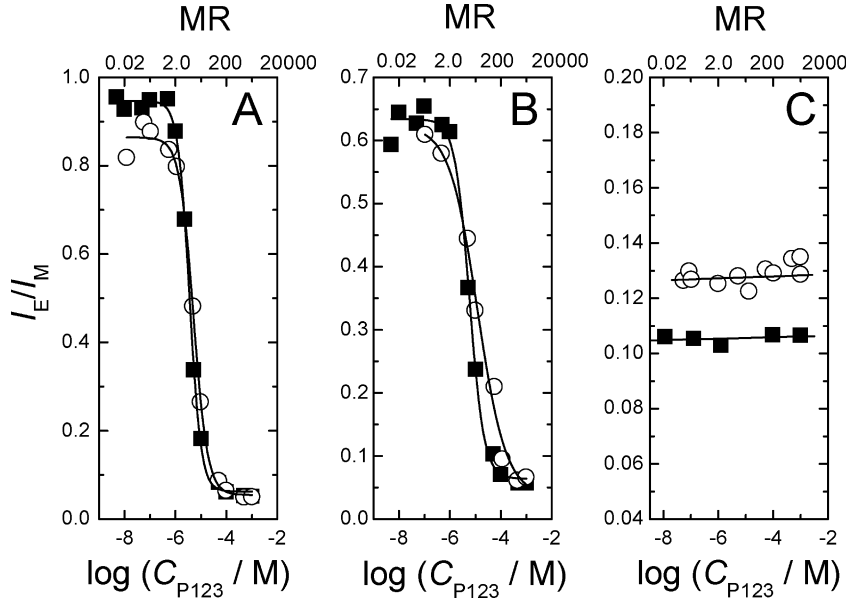

Figure 8. Dependence of the eximer-to-monomer ratio $\left(I_{\mathrm{E}} / I_{\mathrm{M}}\right)$ on the P123 concentration with $(O)$ and without $(\square) \mathrm{NaCl}$, at pH 3.6 (A), pH 5 (B), and (C) $\mathrm{pH}$ 9. At $\mathrm{pH} 3.6$ and 5, the $\mathrm{NaCl}$ concentration used was 1 $\mathrm{mM}$ of $\mathrm{NaCl}$, and at $\mathrm{pH} \mathrm{9}$, it was $10 \mathrm{mM}$. The measurements were performed at $40{ }^{\circ} \mathrm{C}$ and with an excitation wavelength of $335 \mathrm{~nm}$.

$\mathrm{pH} 9$, the obtained $R_{\mathrm{H}, \mathrm{P} 123=0}^{\text {slow }}$ value is $140 \pm 20 \mathrm{~nm}$, which is significantly larger than the value obtained at acidic $\mathrm{pH}$. This is close to $135 \mathrm{~nm}$, which obtained from the slow mode of the PAAMePy55 system at $10 \mathrm{mM}$ without any P123. Furthermore, at all $\mathrm{pH}$ values, the presented errors were determined from the linear fits shown in Figure 7 assuming that the relative error of $R_{\mathrm{H}}$ to be the same as that of $D_{0}$ in each case.

Fluorescence Spectroscopy. Addition of $\mathrm{NaCl}$. The association between the PAAMePy55 polyelectrolyte and the P123 block copolymer studied by fluorescence techniques was the subject of the previous paper. ${ }^{39}$ The fluorescence results clearly showed the existence of association between the two polymers with a concomitant expansion of the polyelectrolyte chain, at acidic $\mathrm{pH}$ values. This observation is confirmed as shown above by the observed increase in the apparent hydrodynamic radius of the PAAMePy55-P123 complex when compared with pure PAAMePy55. In the DLS experiments, the presence of $\mathrm{NaCl}$ was required to screen electrostatic effects, and it is consequently of utmost importance to investigate the influence of $\mathrm{NaCl}$ on the nature of the intra- and intermolecular interactions involved.

The emission spectra of the PAAMePy55-P123 system display the characteristic pyrene emission with a shorter wavelength vibronically resolved band (monomer) coexisting with a broad emission band (excimer) at longer wavelengths. ${ }^{39,78}$ The excimer-to-monomer ratio $\left(I_{\mathrm{E}} / I_{\mathrm{M}}\right)$ plotted as a function of the P123 concentration (readapted from ref 39) is depicted in Figure 8. At $\mathrm{pH} 3.6$, the presence of $1.4 \mathrm{mM}$ of $\mathrm{NaCl}$ has no significant effect on the $I_{\mathrm{E}} / I_{\mathrm{M}}$ curves, meaning that the salt addition does not promote changes in the nature of the (hydrophobic intramolecular) interactions occurring in the system. At pH 5, a slightly different behavior is observed when salt is added, i.e., the range of $\mathrm{P} 123$ concentration at which the decrease of the $I_{\mathrm{E}} / I_{\mathrm{M}}$ ratio occurs becomes broader. This observation means that the expansion of the PAAMePy55 polymer chain due to the presence of P123 block copolymer occurs in a more gradual manner; however, it has no effect in the obtained inflection point of the curve. The differences resulting from $\mathrm{NaCl}$ addition observed at $\mathrm{pH} 5$ are due to the coexistence of protonated and deprotonated carboxylic groups within the PAAMePy55 polymer chain and will be discussed below.

When the $\mathrm{pH}$ is increased $(\mathrm{pH} 9)$, the $I_{\mathrm{E}} / I_{\mathrm{M}}$ ratio remains constant all over the P123 concentration range studied. Never- theless, an increase in $I_{\mathrm{E}} / I_{\mathrm{M}}$ values is observed in the presence of $10 \mathrm{mM}$ of $\mathrm{NaCl}$. At $\mathrm{pH} \mathrm{9,} \mathrm{the} \mathrm{PAA} \mathrm{chain} \mathrm{is} \mathrm{almost} \mathrm{totally}$ deprotonated, and in the state of an expanded conformation due to electrostatic repulsions between the $\mathrm{COO}^{-}$groups. The presence of $\mathrm{NaCl}$ reduces the electrostatic repulsion and thus a more coiled polymer conformation is expected, reflected by an increase of the $I_{\mathrm{E}} / I_{\mathrm{M}}$ ratio (i.e., an increase of the intramolecular pyrene-pyrene hydrophobic interactions).

\section{Discussion}

In the excellent review by Mandel, ${ }^{52}$ several important concentration intervals are discussed and necessary to take into account in order to understand the behavior of highly charged macromolecules in solution and the results from the light scattering investigations. At very low concentrations (dilute regime), when the concentration of the polyelectrolyte in solution $(C)$ is much lower than the critical overlap concentration (denoted $C^{* *}$ in this study), i.e. $C \ll C^{* *}$, the highly charged polyelectrolyte chains (or polyions) are stretched due to the osmotic swelling of the counterions. Due to the low concentration, the stiff polyions are unperturbed in solution and move freely. At a given concentration $C^{*^{\prime}}$, the rotational motion is hindered and a three-dimensional lattice is formed by the rodlike polyions. The concentration regime $C<C^{*^{\prime}}$ is seldom investigated by light scattering techniques due to the low scattering intensity of the solutions. Above $C^{*^{\prime}}$, the further addition of polyelectrolyte causes the lattice to melt (at a critical concentration $C^{*}$ ) due to charge screening in a similar way as addition of simple salt. This regime (i.e., $C^{*}<C<C^{* *}$ ) is sometimes denoted as the transition regime of semiflexible polyions anticipating the semidilute concentration regime of flexible polyions, where the system is found when the concentration increases above $C^{* *}$ and where a transient network is formed.

The DLS measurements performed in the lower concentration part of the transition regime show single exponential correlation functions with one fast relaxation mode. The fast mode has been interpreted as a result of a coupled diffusion of polyions and counterions, see refs 53-56 and 68 and the references therein. Sedlák et al. ${ }^{53}$ described this coupling as the motion of polyions and counterions in a common electrostatic field where the polyions experience an electric force due to the concentration fluctuations of the surrounding counterions. The fast mode diffusion coefficient ( $D_{\text {fast }}$ ) has shown to be independent of the molecular weight and concentration of the polyelectrolyte, ${ }^{53}$ but very dependent on the low molecular weight salt concentration ${ }^{69}$ and of the degree of ionization of the polyelectrolyte chain. ${ }^{65,66,69}$ Therefore, it can be derived that $D_{\text {fast }}$ is mainly determined by the fast diffusion rate of the counterions and that the hydrodynamics of the polyelectrolyte chain plays a minor role.

At higher concentrations in the transition regime (still below $\left.C^{* *}\right)$, a slow mode may appear in the relaxation time distributions. The origin of this mode is still under debate and a number of proposals can be found in the literature. Among these, one seems more consensual and relates the slow mode with the collective diffusion of multichain domains ordered in solution as a result of strong intermolecular interactions, i.e. a static structure factor effect. Factors such as the polyelectrolyte molecular weight ${ }^{53,54,69}$ and concentration, ${ }^{54,69}$ ionic strength, ${ }^{62,65,69}$ solvent, ${ }^{57,64}$ temperature,${ }^{57,66}$ stabilization time, ${ }^{61,63}$ and filtration procedures, made prior to the measurements, ${ }^{60,70}$ were shown to highly influence the formation of these domains.

Semidilute polyelectrolyte systems $\left(C>C^{* *}\right)$ behave similarly to that of uncharged polymer systems and a transient network is formed of the flexible overlapping polyions. The fast 
mode, which is always diffusive, is now instead interpreted as the "gel mode" reflecting the network dynamics and a concerted motion of polymer chains, which in the framework of the blob model $^{71}$ can be characterized by a cooperative diffusion coefficient. $^{52,69}$ The slow relaxation mode becomes more pronounced in this more concentrated regime ${ }^{65,72}$ which, depending whether it is $q$ dependent or not, may be interpreted in various ways, see e.g. ref 73 and the references therein. For some semidilute uncharged polymers in theta solvents ${ }^{49}$ but also in good solvents, ${ }^{74}$ the slow mode has been found to be connected to the disengagement relaxation of individual chains (i.e., viscoelastic relaxation) and it was then $q$ independent. On the other hand, a $q$-dependent $\left(q^{2}\right.$ or with a $q$ dependence stronger than $q^{2}$ ) slow mode has been proposed to be associated with long-range concentration fluctuations of large domains (i.e., cluster relaxation) and can be predicted according to the coupling model of Ngai. ${ }^{75}$ Such a $q$ dependent behavior has been observed both for semidilute polyelectrolyte systems, e.g. refs 65,69 , 70,72 , and 76 as well as for semidilute systems of uncharged polymers, associating polymers and for gelling polymer systems. $^{73,77}$

In our study of the pure labeled and unlabeled PAA systems at $\mathrm{pH}$ 9, we were able to identify the slow and fast diffusion characteristics of polyelectrolyte systems (Figure 3). Hence, we believe that the polyelectrolyte systems of our study are in the higher concentration part of the transition regime (still below $\left.C^{* *}\right)$. The formation of multichain domains is much more favorable at $\mathrm{pH} 9$ and could not be avoided completely by small amounts of $\mathrm{NaCl}$ or the presence of $\mathrm{P} 123$ in the PAAMePy55 solutions at this $\mathrm{pH}$ (see Figures 3 and 4).

Effect of Salt. DLS measurements of the PAAMePy55 polymer were performed at three different $\mathrm{pH}$ values $(3,5$, and 9 ), and strange effects can be observed in the relaxation time distributions of such systems as discussed above. Indeed, these effects are strictly related to electrostatic interactions (i.e., varying with the $\mathrm{pH}$ ) and can be partially avoided by the presence of electrolytes, such as $\mathrm{NaCl}$. Previous studies on the PAAMePy55 polymer ${ }^{78}$ and on similar PAAMePy polymers $\left(M_{\mathrm{n}}\right.$ $=2000$ and $450000 \mathrm{~g} / \mathrm{mol})^{79}$ showed that their conformation in salt-free solutions depends on the balance between the hydrophobic (pyrene-pyrene) and electrostatic (i.e., degree of ionization) interactions. The degree of ionization $(\alpha)$ for PAA polymers is given by the following equation: ${ }^{79,80}$

$$
\mathrm{pH}=6.17-2 \log \left(\frac{1-\alpha}{\alpha}\right)
$$

The comparison of the titration curves presented in ref 79 shows that between $\mathrm{pH} 3$ and 7 the curves of pyrene-labeled polymers are different from that of the untagged polymer, indicating that the hydrophobic labels influence the degree of deionization. At $\mathrm{pH} 3$, the PAAMePy55 polymer chain is almost completely protonated ( $\alpha \sim 0.025$, determined through the eq 5 ), i.e., the chain is in a collapsed state due to the absence of net charge and pyrene-pyrene interactions are predominant. By increasing the $\mathrm{pH}$ to 5 , and consequently the degree of ionization of the PAAMePy55 chain $(\alpha \sim 0.2)$, the entropy of the counterions increases, causing the polymer chain to expand due to the swelling osmotic pressure of the counterions (i.e., an increase in the volume occupied by the counterions) ${ }^{81}$ At $\mathrm{pH} 9$, the PAAMePy55 chain is almost fully ionized $(\alpha \sim 0.96)$ and the electrostatic interactions predominate over the hydrophobic interactions.

The presence of $\mathrm{NaCl}$ has been shown to promote the transition from an expanded to a collapsed state. ${ }^{82}$ However, according to the DLS measurements at acidic $\mathrm{pH}$ presented in this study, the addition of $\mathrm{NaCl}$ to the PAAMePy55-P123 system has little effect on the association between the PAAMePy55 polymer chain and the P123 block copolymer micelles, i.e. the measured hydrodynamic radii values were unaltered. The addition of $\mathrm{NaCl}$ was also reflected in the results from the steady-state fluorescence measurements on the PAAMePy55P123 mixed system (Figure 8). The $I_{\mathrm{E}} / I_{\mathrm{M}}$ ratio is affected by the presence of salt in the system at all $\mathrm{pH}$ values but the effect becomes progressively more pronounced as the $\mathrm{pH}($ and $\alpha)$ is increased. At pH 3.6, minor effects are observed (only a slight increase in the $I_{\mathrm{E}} / I_{\mathrm{M}}$ ratio in the low $\mathrm{P} 123$ concentration regime). At $\mathrm{pH} \mathrm{5,} \mathrm{the} \mathrm{main} \mathrm{effect} \mathrm{is} \mathrm{related} \mathrm{with} \mathrm{the} \mathrm{fact} \mathrm{that} \mathrm{in} \mathrm{the}$ presence of salt, the concentration regime widens in which the association between P123 and PAAMePy55 occurs. A similar behavior was observed by Leyte et al. ${ }^{83}$ in the investigation of the effect of $\mathrm{Na}_{2} \mathrm{CO}_{3}$ concentration on the poly(methacrylate) (PMA) conformational changes. They observed that an increase in the amount of salt results in an enlarged $\mathrm{pH}$ range where a conformational transition occurs. Later on, Leclercq et al. ${ }^{84}$ reported the effect of salt on the thermodynamic properties of an aqueous solution of PMA and of a hydrophobically modified PMA and it was concluded that the presence of salt results in a variation of the conformational entropy change with a consequent increase in the stability of a coiled polymer conformation. Earlier ${ }^{23} \mathrm{Na}$ NMR studies have revealed that there is a strong association between the $\mathrm{Na}^{+}$ion and water. ${ }^{85}$ In our system at $\mathrm{pH} \mathrm{5}$, the presence of the $\mathrm{Na}^{+}$ion (by addition of $\mathrm{NaCl}$ ) most likely results in the formation of complexes between the hydrated $\mathrm{Na}^{+}$ions and the $\mathrm{COOH}$ and $\mathrm{COO}^{-}$groups, which leads to a decrease of the intramolecular repulsive electrostatic interactions. As a consequence of this, the intermolecular interaction between the PAAMePy55 chain and the P123 micelles (and the consequent change in the PAA conformation) is now less effective when compared with the situation without $\mathrm{NaCl}$, due to a cooperative conformational transition from a globular to an expanded coil. ${ }^{85}$

Complex Stoichiometry. It is noticed in Figure 7 that the diffusion coefficient of the complex does not change when the molar ratio is increased at acidic $\mathrm{pH}$ values, i.e. at a fixed P123 concentration $D_{\text {slow }}$ is independent of PAAMePy55 concentration. This shows that the stoichiometry of the complex is independent of the P123 concentration once it is formed and additional P123 addition to the system only leads to more free P123 micelles. Furthermore, the hydrodynamic size of the complex at $\mathrm{pH} 3$ and 5 seems to be the same. When comparing the average value of the hydrodynamic radius $\left(\left\langle R_{\mathrm{H}, \mathrm{P} 123=0}^{\text {slow }}\right\rangle=36\right.$ $\mathrm{nm})$ of the PAAMePy55-P123 complex at acidic $\mathrm{pH}$ values with the apparent radius of $18 \mathrm{~nm}$ of the pure PAAMePy55 polymer chain, a significant increase is observed. The observed increase corresponds to a polymer-coil volume ${ }^{1}$ of ca. 8 times larger than in the absence of P123 micelles. Therefore, and considering the volume occupied by a P123 micelle $(\sim 4850$ $\mathrm{nm}^{3}$ ), this increase implies that the stoichiometry of the complex is, on average, 1:42 PAAMePy55 chain:P123 spherical micelles (see Scheme 1). The pyrene groups of the PAAMePy55 polymer chain are in contact with the PEO corona of the P123 micelle according to the fluorescence data obtained previously. ${ }^{39}$

The $R_{\mathrm{H}, \mathrm{P} 123=0}^{\text {slow }}$ value obtained at $\mathrm{pH} 9\left(R_{\mathrm{H}, \mathrm{P} 123=0}^{\text {slow }}=140 \pm 20\right.$ $\mathrm{nm}$ ) from the slow relaxation mode (see Figure 4C) is too large to be attributed to the translational motion of a single PAAMePy55-P123 complex. Instead it is likely to be caused by the formation of multichain domains, i.e., the intermolecular repulsion exerted by the carboxylate ions $\left(\mathrm{COO}^{-}\right)$force the 
SCHEME 1: Schematic Representation of the
PAAMePy55:P123 System in the High P123
Concentration Regime and at Acidic pH Values

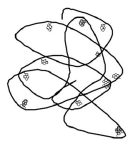

$+\mathrm{P} 123$

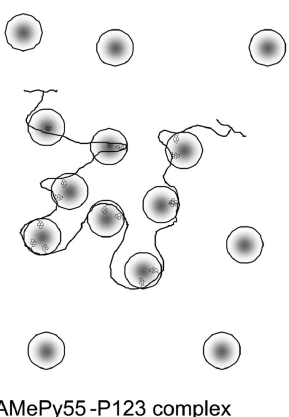

PAAMePy55-P123 complex stretched PAAMePy55 chains to diffuse as a group in a common electric field, appearing as one large object. The $I_{1} / I_{3}$ ratio and the fluorescence decay times ${ }^{39}$ indicate that PAAMePy55 and P123 still associate at this high $\mathrm{pH}$. There are two alternative explanations that can be put forward. First, we may interpret the multichain domains to be formed by PAAMePy55 chains that entrap some of the P123 micelles. The entrapped micelles are then close enough to associate with (or bind to) the polyelectrolyte chains, while the majority diffuse freely in the solution and do not interact with the PAAMePy55 chains. The randomly labeling of the PAAMePy55 chain could lead to an uneven distribution of the pyrene groups along the PAA chain, creating high and low labeled regions. These highly labeled regions constitute preferential sites of association for the P123 micelles at high $\mathrm{pH}$ 9. However, the association between P123 and PAAMePy55 at $\mathrm{pH} 9$ is considered to be minor. This is confirmed by the very low relative amplitude of the slow mode compared to the fast mode in the relaxation time distributions (see Figure 4C). The amplitude of the slow mode is 0.05 . This is a clear indication that the scattering of these large domains contributes very little to the total scattered intensity (only 5\%) due to the fact that the relaxation time distributions are intensity distributions. Moreover, the total scattering intensity of a given sample is always higher at $\mathrm{pH} 3$ than at $\mathrm{pH}$ 9. This means that with the PAAMePy55-P123 micellar complexes at $\mathrm{pH} 9$ the domains are present at a very low number in the solution and thus give a little contribution to the total scattering intensity. It is thus difficult to conclude from the DLS results alone that the multichain domains consist of polyelectrolyte chains with entrapped P123 micelles. A comparison of the size of the polyelectrolyte domains in the absence and presence of $\mathrm{P} 123$ was not possible since their size is dependent on the polyelectrolyte concentration, ${ }^{53,69}$ and a DLS study of the pure PAAMePy55 system at such a low concentrations was not possible to perform due to the low scattering intensity. However, we can conclude that the multichain domains of the pure polyelectrolyte system are not destroyed by the presence of P123 block copolymer micelles.

The second explanation refers to the fact that the PEO-PPOPEO copolymers are polydisperse. We can not exclude that highly hydrophilic diblock PEO-PPO copolymers (with high PEO content) that may not be involved in the micelle formation at $40{ }^{\circ} \mathrm{C}$ can be present in the micellar P123 solution as single copolymer chains, which has been established in recent studies by Hvidt et al. ${ }^{30,35}$ In the mixed case, these diblock impurities can associate with the PAAMePy55 chains. This association will be reflected in the fluorescence data but not in the DLS data. We may then suggest that the multichain domains of the mixed system at $\mathrm{pH} 9$ are the same as those of the pure
PAAMePy55 polymer system. The presence of diblocks does not affect the domains and hence the DLS data stay unchanged. At the present, we are not able to distinguish between these two scenarios unless the P123 sample is purified, which would be the next obvious step of this investigation.

\section{Conclusions}

The intermolecular association between a PAA polymer hydrophobically modified with pyrene (PAAMePy55) and the PEO-PPO-PEO triblock copolymer P123 was studied by dynamic light scattering and by steady-state fluorescence spectroscopy (the comprehensive fluorescence study is reported in ref 39). The previous fluorescence study showed that PAAMePy55 and P123 associate strongly at low pH, leading to the formation of PAAMePy55-P123 complexes, where the pyrene groups are located at the PPO/PEO interface of the P123 micelle. ${ }^{39}$ Another important finding, resulting from the fluorescence investigations, is that no lowering of the $\mathrm{cmc}$ of $\mathrm{P} 123$ is observed upon addition of the PAAMePy55, thus showing that this polymer cannot promote the micellization of P123, i.e., the association occurs at $\mathrm{P} 123$ concentrations higher than the cmc of P123. This shows that the P123 micelles are first formed in solution and the association between the P123 micelles and the PAAMePy55 polymer chains is only effective after achieving a given P123/PAAMePy55 molar ratio. The degree of ionization and consequently the hydrophobicity (and flexibility) of the PAAMePy55 chain were also found to be of major importance for the association: the former is the driving force of the association and the latter determines the extension of the association. The DLS measurements performed in the low molar ratio regime and at acidic $\mathrm{pH}$ values showed that there is no change in the apparent hydrodynamic radius of the PAAMePy55 chain in the mixed system compared to that obtained for the pure PAAMePy55 chain. In the high molar ratio regime and at acidic $\mathrm{pH}$, bimodal relaxation time distributions were obtained, which corresponded to the diffusion of free P123 micelles and of PAAMePy55-P123 complexes, respectively. From the DLS studies at acidic $\mathrm{pH}$, the hydrodynamic size of PAAMePy55-P123 complex formed was determined, and which implied that the complex consists of one single PAAMePy55 chain with 42 P123 micelles associated to it. At $\mathrm{pH}$ 9, the relaxation time distributions revealed the presence of a short number of large domains formed by several PAAMePy55 chains, which are characteristic of polyelectrolyte systems in addition to free P123 micelles that are in the majority in number. The presence of P123 did not lead to the total disruption of these domains. Unless the P123 sample is purified, no final conclusions can be drawn of the structure of these domains since they may either originate from several PAAMePy55 chains with a few entrapped P123 micelles or several polyelectrolyte chains that associate with unassociated diblock impurities that are not involved in the micellization process of P123. However, we may conclude that the association between P123 and PAAMePy55 is minor at high pH as compared to acidic $\mathrm{pH}$ values.

In this study of a polyelectrolyte-block copolymer system, we have shown that a good agreement (and complementary information) can be obtained from the DLS and fluorescence approaches. The concentration at which the two polymers begin to have a significant degree of association (even at high $\mathrm{pH}$ ) could be easily detected in the fluorescence studies, and the data also indicated that the preferentially location of the pyrene groups of the PAAMePy55 polymer is found enclosed in the P123 micelles. 
Acknowledgment. We wish to acknowledge the financial support from the Swedish Research Council (VR) and the Linneaus Center of Excellence "Organizing Molecular Matter" through VR (to K.S.) and the Portuguese Science Foundation (projects POCI/QUI/58689/2004 and PTDC/QUI/67962/2006) (to J.S.d.M.). T.C. acknowledges FCT for a Ph.D. grant (SFRH/ $\mathrm{BD} / 17852 / 2004)$.

\section{References and Notes}

(1) Evans, D. F.; Wennerstrom, H., The Colloidal Domain: Where Physics, Chemistry, Biology, and Technology Meet; Wiley-VCH: New York, 1999.

(2) Jönsson, B.; Lindman, B.; Holmberg, K.; Kronberg, B. Surfactants and Polymers in Aqueous Solution, 2nd ed.; John Wiley \& Sons: Chichester, 1998.

(3) Schillén, K.; Anghel, D. F.; Miguel, M. D.; Lindman, B. Langmuir 2000, 16, 10528 .

(4) Fundin, J.; Hansson, P.; Brown, W.; Lidegran, I. Macromolecules 1997, 30, 1118.

(5) Robb, I. D.; Stevenson, P. Langmuir 2000, 16, 7168.

(6) Cole, M. L.; Whateley, T. L. J. Colloid Interface Sci. 1996, 180, 421.

(7) Anghel, D. F.; Saito, S.; Baran, A. Langmuir 1998, 14, 5342.

(8) D’Errico, G.; Ciccarelli, D.; Ortona, O.; Paduano, L.; Sartorio, R. J. Colloid Interface Sci. 2004, 270, 490.

(9) Winnik, F. M.; Ringsdorf, H.; Venzmer, J. Langmuir 1991, 7, 912.

(10) Khutoryanskiy, V. V.; Mun, G. A.; Nurkeeva, Z. S.; Dubolazov,

A. V. Polym. Int. 2004, 53, 1382.

(11) Chu, B. Langmuir 1995, 11, 414.

(12) Chu, B.; Zhou, Z. In Nonionic surfactants: polyoxyalkylene block copolymers; Nace, V. M., Dekker, M., Eds.; Marcel-Dekker, Inc.: New York, 1996; p 67.

(13) Alexandridis, P.; Hatton, T. A. Colloids Surf. A 1995, 96, 1.

(14) Almgren, M.; Brown, W.; Hvidt, S. Colloid Polym. Sci. 1995, 273, 2.

(15) Alexandridis, P.; Lindman, B. Amphiphilic Block Copolymers: SelfAssembly and Applications; Elsevier: Amsterdam, 1997.

(16) Nagarajan, R.; Barry, M.; Ruckenstein, E. Langmuir 1986, 2, 210.

(17) Brown, W.; Schillén, K.; Almgren, M.; Hvidt, S.; Bahadur, P. J. Phys. Chem. 1991, 95, 1850.

(18) Brown, W.; Schillén, K.; Hvidt, S. J. Phys. Chem. 1992, 96, 6038. (19) Mortensen, K.; Brown, W. Macromolecules 1993, 26, 4128.

(20) Glatter, O.; Scherf, G.; Schillén, K.; Brown, W. Macromolecules 1994, 27, 6046.

(21) Pedersen, J.; Gerstenberg, M. Macromolecules 1996, 29, 1363.

(22) Pedersen, J.; Gerstenberg, M. Colloids Surf. A 2003, 213, 175.

(23) Goldmints, I.; von Gottberg, F. K.; Smith, K. A.; Hatton, T. A. Langmuir 1997, 13, 3659 .

(24) Goldmints, I.; Yu, G.; Booth, C.; Smith, K. A.; Hatton, T. A. Langmuir 1999, 15, 1651.

(25) Jansson, J.; Schillén, K.; Nilsson, M.; Söderman, O.; Fritz, G.; Bergmann, A.; Glatter, O. J. Phys. Chem. B 2005, 109, 7073.

(26) Mortensen, K. Polymers Adv. Technol. 2001, 12, 2.

(27) Wanka, G.; Hoffmann, H.; Ulbricht, W. Macromolecules 1994, 27, 4145 .

(28) Beezer, A.; Loh, W.; Mitchell, J.; Royall, P.; Smith, D.; Tute, M.; Armstrong, J.; Chowdhry, B.; Leharne, S.; Eagland, D.; Crowder, N. Langmuir 1994, 10, 4001.

(29) da Silva, R. C.; Olofsson, G.; Schillén, K.; Loh, W. J. Phys. Chem. B 2002, 106, 1239 .

(30) Batsberg, W.; Ndoni, S.; Trandum, C.; Hvidt, S. Macromolecules 2004, 37, 2965.

(31) Jansson, J.; Schillén, K.; Olofsson, G.; da Silva, R. C.; Loh, W. J. Phys. Chem. B 2004, 108, 82.

(32) Nilsson, M.; Håkansson, B.; Söderman, O.; Topgaard, D. Macromolecules 2007, 40, 8250.

(33) Linse, P. Macromolecules 1994, 27, 2685.

(34) Linse, P. Macromolecules 1994, 27, 6404.

(35) Hvidt, S.; Batsberg, W. Int. J. Polym. Anal. Chem. 2007, 12, 13

(36) Mortensen, K.; Batsberg, W.; Hvidt, S. Macromolecules 2008, 41, 1720.

(37) Khutoryanskiy, V. V.; Dubolazov, A. V.; Nurkeeva, Z. S.; Mun, G. A. Langmuir 2004, 20, 3785. 1045 .
(39) Costa, T.; Schillén, K.; Miguel, M. G.; Lindman, B.; Seixas de Melo, J. J. Phys. Chem. B 2009, 113, 6194.

(40) Löf, D.; Niemiec, A.; Schillén, K.; Loh, W.; Olofsson, G. J. Phys. Chem. B 2007, 111, 5911.

(41) Löf, D.; Schillén, K.; Torres, M. F.; Müller, A. J. Langmuir 2007, 23, 11000 .

(42) Schillén, K.; Jansson, J.; Löf, D.; Costa, T. J. Phys. Chem. B 2008, $112,5551$.

(43) Löf, D.; Tomšič, M.; Glatter, O.; Fritz-Popovski, G.; Schillén, K. J. Phys. Chem. B, ASAP. DOI: 10.1021/jp808442d.

(44) Anghel, D. F.; Alderson, V.; Winnik, F. M.; Mizusaki, M.; Morishima, Y. Polymer 1998, 39, 3035.

(45) Jakěs, J. Czech. J. Phys. 1988, 38, 1305.

(46) Berne, B. J.; Pecora, R. Dynamic Light Scattering: with Applications to Chemistry, Biology and Physics, 2nd ed.; Dover Publications, Inc.: New York, 2000.

(47) Štěpánek, P. In Dynamic Light Scattering: The Method and Some Applications, Brown, W., Ed.; Oxford University Press: Oxford, 1993; p 177.

(48) Johnsen, R. M.; Brown, W. In Laser Light Scattering in Biochemistry, Harding, S. E., Sattelle, D. B., Bloomfield, V. A., Eds.; The Royal Society of Chemistry, Thomas Graham House, Science Park: Cambridge, 1992.

(49) Brown, W.; Nicolai, T. In Dynamic Light Scattering: The Method and Some Applications; Brown, W., Ed.; Oxford University Press: Oxford, 1993.

(50) Ganguly, R.; Aswal, V. K.; Hassan, P. A. J. Colloid Interface Sci. 2007, 315, 683 .

(51) Denkova, A. G.; Mendes, E.; Coppens, M.-O. J. Phys. Chem. B 2008, 112, 793.

(52) Mandel, M. In Dynamic Light Scattering: The Method and Some applications; Brown, W., Ed.; Clarendon Press: Oxford, 1993.

(53) Sedlák, M.; Amis, E. J. J. Chem. Phys. 1992, 96, 817.

(54) Sedlák, M.; Amis, E. J. J. Chem. Phys. 1992, 96, 826.

(55) Sedlák, M. J. Chem. Phys. 1997, 107, 10799.

(56) Chang, R.; Yethiraj, A. J. Chem. Phys. 2002, 116, 5284.

(57) Sedlák, M. J. Chem. Phys. 1994, 101, 10140.

(58) Sedlák, M. J. Chem. Phys. 1997, 107, 10805.

(59) Sedlák, M. Langmuir 1999, 15, 4045.

(60) Sedlák, M. J. Chem. Phys. 2002, 116, 5236.

(61) Sedlák, M. J. Chem. Phys. 2002, 116, 5246.

(62) Sedlák, M. J. Chem. Phys. 2002, 116, 5256.

(63) Sedlák, M. J. Chem. Phys. 2005, 122, 151102.

(64) Sedlák, M.; Koňák, C.; Labsky, J. Polymer 1991, 32, 1688. 873.

(65) Sedlák, M.; Koňák, C.; Štěpánek, P.; Jakěs, J. Polymer 1987, 28,

(66) Sedlák, M.; Koňák, C.; Štěpánek, P.; Jakěs, J. Polymer 1990, 31, 253-257.

(67) Adamczyk, Z.; Bratek, A.; Jachimska, B.; Jasinski, T.; Warszynski, P. J. Phys. Chem. B 2006, 110, 22426.

(68) Tanahatoe, J. J.; Kuil, M. E. J. Phys. Chem. A 1997, 101, 8389.

(69) Förster, S.; Schmidt, M.; Antonietti, M. Polymer 1990, 31, 781.

(70) Tanahatoe, J. J.; Kuil, M. E. J. Phys. Chem. B 1997, 101, 10839.

(71) de Gennes, P. G. Scaling Concepts in Polymer Physics; Cornell University Press: Ithaca, NY,1979.

(72) Buhler, E.; Rinaudo, M. Macromolecules 2000, 33, 2098.

(73) Nyström, B.; Lindman, B. Macromolecules 1995, 28, 967.

(74) Wang, C. H.; Zhang, X. Q. Macromolecules 1993, 26, 707.

(75) Ngai, K. Adv. Colloid Interface Sci. 1996, 64, 1.

(76) Tanahatoe, J. J.; Kuil, M. E. J. Phys. Chem. B 1997, 101, 9233.

(77) Kjøniksen, A.-L.; Nyström, B. Macromolecules 1996, 29, 7116.

(78) Seixas de Melo, J.; Costa, T.; Miguel, M. D.; Lindman, B.; Schillén,

K. J. Phys. Chem. B 2003, 107, 12605.

(79) Seixas de Melo, J.; Francisco, A.; Costa, T.; Maçanita, A.; Gago,

S.; Gonçalves, I. S. PCCP 2007, 9, 1370.

(80) Katchalsky, A.; Spitnik, P. J. Polym. Sci. 1947, 2, 432.

(81) Volkov, E. V.; Fillippova, O. E.; Khokhlov, A. R. Colloid J. 2004, 66, 663.

(82) Volkov, E. V.; Filippova, O. E.; Khokhlov, A. R. Colloid J. 2004, $66,669$.

(83) Leyte, J. C.; Mandel, M. J. Polym. Sci., Part A: Gen. Pap. 1964, 2, 1879 .

(84) Leclercq, L.; Pollet, A.; Morcellet, M.; Martel, B. Eur. Polym. J. $1999,35,185$.

(85) Gustavsson, H.; Lindman, B.; Tornell, B. Chem. Scripta 1976, 10, 136.

JP8093885 